\title{
Constructal Design of Elliptical Cylinders with Heat Generating for Entropy Generation Minimization
}

\author{
Rong Wang ${ }^{1,2,3}$, Zhihui Xie ${ }^{1,2,3, *}$, Yong Yin ${ }^{2,3}$ and Lingen Chen ${ }^{2,3, *(1)}$ \\ 1 College of Power Engineering, Naval University of Engineering, Wuhan 430033, China; \\ hjgcdxwangrong@163.com \\ 2 Institute of Thermal Science and Power Engineering, Wuhan Institute of Technology, Wuhan 430205, China; \\ yinyongwit@163.com \\ 3 School of Mechanical \& Electrical Engineering, Wuhan Institute of Technology, Wuhan 430205, China \\ * Correspondence: zhihui-xie@163.com (Z.X.); lgchenna@yahoo.com or lingenchen@hotmail.com (L.C.)
}

Received: 14 April 2020; Accepted: 8 June 2020; Published: 12 June 2020

\begin{abstract}
A heat dissipation model of discrete elliptical cylinders with heat generation on a thermal conduction pedestal cooled by forced convection is established. Constructal design is conducted numerically by taking the distributions of thermal conductivity and heat generating intensity as design variables, the dimensionless entropy generation rate (DEGR) as performance indicator. The optimal designs for discrete elliptical cylinders with heat generating are obtained respectively, i.e., there are optimal distributions of heat generating intensity with its fixed total amount of heat sources, and there are optimal distributions of thermal conductivity with its fixed total amount of heat sources. These optimums for minimum DEGRs are different at different Reynolds numbers of airflow. The heat generating intensity can be decreased one by one appropriately in the fluid flow direction to achieve the best effect. When the Reynolds number of airflow is smaller, the thermal conductivity of heat source can be increased one by one appropriately in the fluid flow direction to achieve the best effect; when the Reynolds number of airflow is larger, the thermal conductivity of each heat source should be equalized to achieve the best effect. The results can give thermal design guidelines for the practical heat generating devices with different materials and heat generating intensities.
\end{abstract}

Keywords: constructal theory; entropy generation minimization; electronics cooling; discrete elliptical cylinder; heat source; generalized thermodynamic optimization

\section{Introduction}

Electronic manufacture technology has developed quickly, and as electronic devices and equipment have been continually and highly miniaturized and integrated, the power per unit volume of the devices has increased continually, which has made their heat dissipation problems increasingly prominent. Research aiming to optimize electronic device and heat sink designs to enhance their heat dissipation has attracted the interest of many scholars [1,2]. In recent years, extensive and in-depth investigations for heat transfer optimization in the light of constructal theory [3-24] and entropy generation minimization [25-60] have flourished, which are beneficial for technologic development of electronics cooling.

Bejan, who investigated the universal physical mechanism of various natural dendritic structures [4-6,9-22,24], found the constructal law and proposed constructal theory from analyzing the formation and evolution of street network configurations in major cities around the world as an example in 1996 [3]. Constructal theory was firstly applied to design an optimal network of high conductivity material for electronics cooling, and the constructal law was found correspondingly [4]. The constructal law [4] stated that, "For a finite-size flow system to persist in time (to live), its configuration must change 
in time such that it provides easier and easier access to its currents." For everything in nature, society and engineering, the configuration evolution in time follows this deterministic physics law [3-24]. Constructal theory not only accounts for and predicts the flow pattern/configuration evolution in nature and society, but also provides theoretical guidelines for the flow pattern/configuration design in various disciplines. The statement of constructal law can be further simplified as "the structures of matters come from their optimal performances [6]." The purpose of constructal design is to seek the optimal configuration with the best distribution of imperfections, so it was also named as a new philosophy of geometry.

For heat transfer optimization, the studies following constructal law can be classified as single-objective optimization, multi-objective optimization and multi-disciplinary optimization by optimization objectives; and these also can be classified as heat conduction optimization, convective heat and mass transfer optimization and various device and component optimization by study objects, and so on [4-6,9-22,24]. It has also been applied to the designs of cavities and fin heat sinks [24,61-63], channel heat sinks [64,65], heat exchangers [66-69], nonuniform heat generating units [70,71], evaporators [72-74], boiler superheater [75], tubular arrangements [76,77], dual-pressure turbine $[78,79]$, etc., in recent years. For the constructal design in engineering, heat sources [80-92] is one of important and interesting research hotspots.

Da Silva and Gosselin [80] pointed out that increasing the cooling channel number doesn't necessarily enhance the heat dissipation by investigating the constructal design of square components with heat generation in cooling channels. Gong et al. [81-83] investigated the constructal designs for two types of cylinders with heat generating which surrounded with a fin under the conditions of natural cooling, forced cooling and uniform heat transfer coefficient, respectively. Jassim and Muzychka [84] indicated that the non-uniform distribution of heat sources had better heat dissipation performance than that of uniform distribution. Tye-Gingra et al. [85] optimized the initial phase of heat flux density's function and position of heat source by establishing a heat source model with sinusoidal variation over time of heat generating intensity. Shi and Dong [86] explored the constructal layout of discrete components with heat generating subjected to forced laminar flow. Fan et al. [87] calculated the heat dissipation performance with single and discrete cylindrical heat sources numerically and the results showed that the performances of multi-scale geometry and non-equal distribution of heat generating intensity were better than those of the single-scale geometry and equal distribution of heat generating intensity. Wang et al. [88] carried out the constructal design for several heat source models including discrete stationary and rotating cylinders, singe and discrete elliptical tables. Sarper et al. [89] investigated the constructal design for discrete multi-scale length heat sources in vertical ducts. In addition, Chen et al. [90], Aslan et al. [91] and Armaghani et al. [92] investigated the heat source layout designs.

Practical processes, such as fluid flow with finite pressure difference and heat transfer with finite temperature difference, are non-equilibrium irreversible processes from the thermodynamic point of view. Bejan $[25,26]$ first derived the corresponding entropy generation rate (EGR) formula for fluid flow with finite pressure difference and heat transfer with finite temperature difference, and proposed the principle of entropy generation minimization (EGM). Many scholars [27-46] have performed extensive and in-depth researches on various processes [32,42], cycles [28,29,36,37], devices [30,31,35,40] and systems [44-46] based on EGM. Recently, various fluid flows such as Newtonian flow [93], carbon nanotube flow [94] and Darcy-Forchheimer nanofluid flow [95], microchannel heat sinks [96], heat exchangers [97-99], and so on, have been investigated with EGM. The conventional metrics, such as the heat transfer enhancement and pressure drop, evaluate convective heat transfer from the view point of the first law of thermodynamics, while the entropy generation analysis is from the view point of the second law of thermodynamics by uniformly characterizing the irreversibility of heat transfer and fluid friction. The purpose of entropy generation minimization is to seek the minimization of thermodynamic irreversibility which is characterized and quantified by the indicators such as entropy generation rate, entropy generation number, Bejan number, and so on [44-46]. 
From the references mentioned above, although the constructal design and entropy generation minimization have respective theoretical connotations, core positions and optimization purposes, one can see that there are internal physical relations between optimal configuration and entropy generation minimization for various heat and mass transfer processes and systems $[6,9,10,13,14,18,19,22,24,31,34]$, and there is a very interesting research content in thermal design employing the method that combining constructal theory with entropy generation minimization for heat source optimization $[87,88]$. The heat sources mentioned in [80-92] were usually cylinders, square columns, elliptical tables, embedded plate structures, and so on. Based on the above combining method, this paper will establish a 3-D heat dissipation model of discrete elliptical cylinders with heat generating, and design heat generating intensity distribution and thermal conductivity distribution to reach the minimum total DEGR of system. This method herein can be adapted to the thermal design requirements of heat sources with different cross-section shapes in practical applications, and especially help to provide theoretical guidelines for the optimization of practical electronic components with different materials and heat generating intensities.

\section{Heat Source Model and Numerical Method}

\subsection{Geometric Model}

Figure 1 gives a geometric model of discrete elliptical cylinders with heat generating on a thermal conduction pedestal with forced convection in a rectangular channel. The length $(L)$, width $(W)$ and thickness $(H)$ of thermal conduction pedestal is 60,20 and $1 \mathrm{~mm}$, respectively. Four equal-size discrete heat sources (numbered 1, 2, 3, and 4 from left to right) are evenly arranged along the central axis of pedestal, wherein the ellipse short axis $\left(L_{\mathrm{a}}\right)$ of the heat source bottom surface is $2.5 \mathrm{~mm}$, the ellipse long axis $\left(L_{\mathrm{b}}\right)$ is $5 \mathrm{~mm}$, and the height $H_{\mathrm{s}}$ of the heat source is $5 \mathrm{~mm}$. The elliptical cylinders can only be arranged in line to meet some multi-disciplinary requirements for manufacture and performance in a practical engineering case.

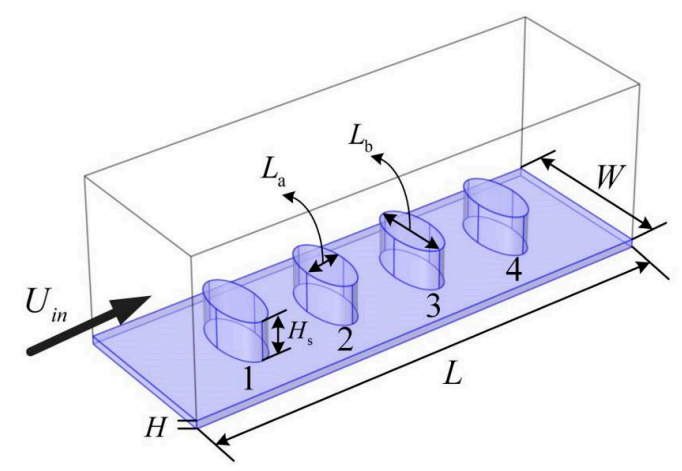

Figure 1. Geometric model of heat sources.

\subsection{Heat Transfer Model}

The reference material of heat conductive pedestal is silicon $\left(c_{\mathrm{b}}\right.$ is $700 \mathrm{~J} \cdot \mathrm{kg}^{-1} \cdot \mathrm{K}^{-1}, \rho_{\mathrm{b}}$ is $2329 \mathrm{~kg} \cdot \mathrm{m}^{3}$, and $\lambda_{\mathrm{b}}$ is $\left.130 \mathrm{~W} \cdot \mathrm{m}^{-1} \cdot \mathrm{K}^{-1}\right)$, the reference material of heat source is copper $\left(c_{\mathrm{s}}\right.$ is $385 \mathrm{~J} \cdot \mathrm{kg}^{-1} \cdot \mathrm{K}^{-1}, \rho_{\mathrm{b}}$ is $8960 \mathrm{~kg} \cdot \mathrm{m}^{3}, \lambda_{\mathrm{s}}$ is $\left.400 \mathrm{~W} \cdot \mathrm{m}^{-1} \cdot \mathrm{K}^{-1}\right)$. The cooling medium through the rectangular channel is clean air, and the variable properties and viscosity dissipation of airflow are considered. The contact surfaces between airflow and channel wall, as well as that between airflow and heat source are all set with non-slip boundaries. The outer wall surfaces of channel and the bottom surface of pedestal are all set with adiabatic boundary conditions. The end faces at inlet and exit of the channel are open boundaries, and the ambient air temperature is set as $T_{\text {in }}(293.15 \mathrm{~K})$. The range of Prandtl number of air is $0.938-0.973$. The forced airflow is a compressible steady-state turbulent flow, and the inlet airflow is perpendicular to the inlet end face. 
The total EGR $[25,26,44]$ of overall heat transfer process is generally clarified as the EGR of solid section and the EGR of fluid section, i.e.,:

$$
S_{\mathrm{g}, \phi}=S_{\text {solid }}+S_{\text {fluid }}
$$

The EGR of solid section $[25,26,44]$ is:

$$
S_{\text {solid }}=-\int_{V} \frac{1}{T^{2}} q \cdot \nabla T d V
$$

The EGR of fluid section $[25,26,44]$ is:

$$
S_{\text {fluid }}=\int_{V}\left(-\frac{1}{T^{2}} q \cdot \nabla T+\frac{\mu}{T} \Phi\right) d V
$$

where $q\left(\mathrm{~W} \cdot \mathrm{m}^{-2}\right)$ is the heat flux vector and $\Phi$ is a viscous dissipation function per unit volume. In the brackets of the right side of Equation (3), the first term is the EGR of heat transfer, and the second term is the EGR of fluid viscous dissipation.

According to Equations (1)-(3), the total EGR of system is:

$$
S_{\mathbf{g}, \boldsymbol{\phi}}=-\int_{V_{s}} \frac{1}{T^{2}} \boldsymbol{q}_{s} \cdot \nabla T d V-\int_{V_{b}} \frac{1}{T^{2}} \boldsymbol{q}_{b} \cdot \nabla T d V+\int_{V_{f}}\left(-\frac{1}{T^{2}} \boldsymbol{q}_{f} \cdot \nabla T+\frac{\mu}{T} \Phi\right) d V
$$

where $q_{\mathrm{s}}, q_{\mathrm{b}}$ and $q_{\mathrm{f}}$ are the heat flux vectors of heat sources, pedestal and fluid, respectively. $V_{\mathrm{s}}, V_{\mathrm{b}}$ and $V_{\mathrm{f}}$ are the volumes of the heat sources, pedestal and fluid, respectively.

According to Equation (4), the dimensionless entropy generation rate (DEGR) of system can be defined as:

$$
\widetilde{S}_{\mathbf{g}, \phi}=\frac{S_{\mathbf{g}, \phi} \cdot T_{\text {in }}}{P_{t}}
$$

The energy equation for solid pedestal with steady-state heat conduction and constant properties is:

$$
\nabla^{2} T=0
$$

The energy equation for heat sources with steady-state heat conduction and constant properties is:

$$
\nabla^{2} T+\frac{q^{\prime \prime}}{\lambda_{\mathrm{s}}}=0
$$

Under forced convection condition, the governing equations of continuous fluid flow, momentum transfer, energy transfer and turbulence characteristics are as follows:

$$
\begin{gathered}
\nabla(\rho \boldsymbol{U})=0 \\
\rho(\boldsymbol{U} \cdot \nabla) \boldsymbol{U}=\nabla \cdot\left[-p \mathbf{I}+\left(\mu+\mu_{\mathrm{T}}\right)\left(\nabla \boldsymbol{U}+(\nabla \boldsymbol{U})^{T}\right)\right. \\
\left.-\frac{2}{3}\left(\mu+\mu_{\mathrm{T}}\right)(\nabla \cdot \boldsymbol{U}) \mathbf{I}-\frac{2}{3} \rho k \mathbf{I}\right]+\boldsymbol{F} \\
\rho c_{f} \boldsymbol{U} \cdot \nabla T+\nabla \cdot \boldsymbol{q}=Q \\
\rho(\boldsymbol{U} \cdot \nabla) k=\nabla \cdot\left[\left(\mu+\frac{\mu_{\mathrm{T}}}{\sigma_{\mathrm{k}}}\right) \nabla k\right]+P_{\mathrm{k}}-\rho \varepsilon \\
\rho(\boldsymbol{U} \cdot \nabla) \varepsilon=\nabla \cdot\left[\left(\mu+\frac{\mu_{\mathrm{T}}}{\sigma_{\varepsilon}}\right) \nabla \varepsilon\right]+C_{\varepsilon 1} \frac{\varepsilon}{k} P_{\mathrm{k}}-C_{\varepsilon 2} \rho \frac{\varepsilon^{2}}{k}
\end{gathered}
$$




$$
\begin{gathered}
\mu_{\mathrm{T}}=\rho C_{\mu} \frac{k^{2}}{\varepsilon} \\
P_{\mathrm{k}}=\mu_{\mathrm{T}}\left[\nabla \boldsymbol{U}:\left(\nabla \boldsymbol{U}+(\nabla \boldsymbol{U})^{T}\right)-\frac{2}{3}(\nabla \cdot \boldsymbol{U})^{2}\right]-\frac{2}{3} \rho k \nabla \cdot \boldsymbol{U}
\end{gathered}
$$

where the parameters with pulsation are all time-averaged. The empirical constants $C_{\varepsilon 1}, C_{\varepsilon 2}, C_{\mu}, \sigma_{\mathrm{k}}$ and $\sigma_{\varepsilon}$ are $1.44,1.92,0.09$ and 1.3 , respectively.

The performance indicator for optimization is the total DEGR of system. The smaller the total DEGR of system, the better the thermodynamic performance of system.

\subsection{Numerical Method}

The governing equations and boundary conditions of the heat dissipation model are solved by the finite element calculation method [100]. The tetrahedral meshing is performed in solid and fluid regions of the model, respectively. For reducing calculation deviations, the grid independence is tested. In the test case, the heat generating intensities $\left(q^{\prime \prime}=1.52 \times 10^{7} \mathrm{~W} \cdot \mathrm{m}^{-3}\right)$ and the thermal conductivities $\left(\lambda_{\mathrm{s}}=200 \mathrm{~W} \cdot \mathrm{m}^{-1} \cdot \mathrm{K}^{-1}\right)$ of four heat sources are equal, and the inlet Reynolds number is set as 5000 . There are three types of meshing with different grid numbers for computations, which are 12047, 52054 and 71006. The total DEGRs of system are $0.0170770,0.0170654$ and 0.0170732 , and the relative errors are $0.068 \%$ and $0.046 \%$, respectively. In order to balance the computation accuracy and efficiency, this paper uses the meshing criterion corresponding to 52054 grids for the following calculations. The general default convergence criteria for the continuity, momentum as well as energy equations are employed [100].

Reynolds Averaged Navier-Stokes (RANS) method is used to perform high-fidelity turbulence simulation calculations by Comsol Multiphysics. To further assess the accuracy of the computational model in this paper, 3-D models of cylindrical heat sources surrounded by fins with different dimensionless height $\widetilde{H}$ and ratio $b$ (the center-to-center distance of the fin and heat source to the radius of fin) in [82] are built for comparative calculations. The numerical results about dimensionless hot spot temperature $\widetilde{T}$ are listed in Table 1 .

Table 1. The influences of $\widetilde{H}$ and $b$ on $\widetilde{T}$.

\begin{tabular}{ccc}
\hline$\widetilde{\boldsymbol{H}}$ & $\mathbf{0 . 1}$ & $\mathbf{0 . 2}$ \\
\hline$b$ & 0.4652 & 0.4835 \\
$\widetilde{T}[82]$ & 7.2339 & 13.6509 \\
$\widetilde{T}$ of this work & 7.1805 & 13.8243 \\
\hline
\end{tabular}

For the same $\widetilde{H}$ and $b$, the maximum difference of $\widetilde{T}$ is only $1.27 \%$, which means that the results herein agree well with the calculation results in [82]. The model of discrete elliptical cylinders with heat generating in this paper is established by the same method, so the effectiveness of the simulation method is verified.

\section{Results and Analyses}

Discrete electronic components with fixed positions always have various heat generating intensities and are made of different materials. Under forced convection conditions, the thermal conductivity distribution and the heat generating intensity distribution are chosen as design variables with the fixed total thermal conductivity and the fixed total heat generating intensity of heat sources, respectively. The constructal design of discrete elliptical cylinders with heat generating is conducted by taking the total dimensionless entropy generation rate minimization as performance indicator. 


\subsection{Effects of Heat Generating Intensity on Heat Dissipation Performance}

The heat generating intensities from top to bottom are set as $q_{1}^{\prime \prime}, q_{2}^{\prime \prime}, q_{3}^{\prime \prime}$, and $q_{4}^{\prime \prime}$, respectively. The distribution is expressed as:

$$
q_{2}^{\prime \prime}-q_{1}^{\prime \prime}=q_{3}^{\prime \prime}-q_{2}^{\prime \prime}=q_{4}^{\prime \prime}-q_{3}^{\prime \prime}=\Delta q^{\prime \prime}
$$

where $\Delta q^{\prime \prime}$ is the difference of heat generating intensity.

The total heat generating intensity of heat sources is fixed, the total heating rate of the heat sources is $P_{\mathrm{t}}(48 \mathrm{~W})$, so the heat generating intensity of each heat source is:

$$
q^{\prime \prime}{ }_{i}=15.2 \times 10^{6}+(\mathrm{i}-2.5) \Delta q^{\prime \prime}
$$

The influence of $\Delta q^{\prime \prime}$ on $\widetilde{S}_{\mathrm{g}, \phi}$ of the system is shown in Figure 2 with the fixed equal thermal conductivity $\left(400 \mathrm{~W} \cdot \mathrm{m}^{-1} \cdot \mathrm{K}^{-1}\right)$ for each heat source. The results show that the higher the Reynolds number $(R e)$, the smaller the system temperature gradient, which makes the total DEGR $\left(\widetilde{S}_{\mathrm{g}, \phi}\right)$ reduce with the increase of airflow $R e$ for specified heat generating intensity distribution. At the same $R e$, as the $\Delta q^{\prime \prime}$ increases, the $\widetilde{S}_{\mathrm{g}, \phi}$ decreases firstly and then increases, the optimal difference $\left(\Delta q_{\mathrm{opt}}^{\prime \prime}\right)$ of heat generating intensity makes $\widetilde{S}_{\mathrm{g}, \phi}$ minimum. $\widetilde{S}_{\mathrm{g}, \phi}$ at $\Delta q^{\prime \prime}=-10 \times 10^{6} \mathrm{~W} \cdot \mathrm{m}^{-1} \cdot \mathrm{K}^{-1}$ is larger than that at $\Delta q^{\prime \prime}=1010^{6} \mathrm{~W} \cdot \mathrm{m}^{-3}$, which means that the heat generating intensity is preferably distributed from large to small in the airflow direction, the device with higher heat generating intensity should be arranged near the channel inlet. Furthermore, numerical results listed in Table 2 show that optimal differences $\left(\Delta q_{\mathrm{opt}}^{\prime \prime} s\right)$ for the same optimization objective are different under different fluid flow conditions. From Table 2, all $\Delta q_{\mathrm{opt}}^{\prime \prime} \mathrm{s}$ are a little bit less than 0 . There is a very thin boundary layer improves the heat transfer at the upstream body and thus reduces temperature gradients. The three downstream bodies are affected by the weakening of upstream body. That is the upstream body could tolerate a higher heat flow rate than its downstream fellows. When $\Delta q^{\prime \prime}$ is close to the $\Delta q_{\text {opt }}^{\prime \prime}$ vaue, the cooling capacity of air on the part with high heat load is also strong, and it is relatively easy to avoid insufficient cooling of the part with high heat load. When $\Delta q^{\prime \prime}$ is less than $\Delta q_{\text {opt }}^{\prime \prime}, \widetilde{S}_{\mathrm{g}, \phi}$ increases when $\Delta q^{\prime \prime}$ decreases. This is because the effect of heat generating intensity distribution on temperature gradient is more significant compared with that of boundary layer.

Table 2. The optimal distributions of heat generating intensity for different $R e$.

\begin{tabular}{ccccc}
\hline $\boldsymbol{R e}$ & $\mathbf{3 0 0 0}$ & $\mathbf{4 0 0 0}$ & $\mathbf{5 0 0 0}$ & $\mathbf{6 0 0 0}$ \\
\hline$\Delta q_{\mathrm{opt}}^{\prime \prime} / 10^{6} \mathrm{~W} \cdot \mathrm{m}^{-3}$ & -0.6 & -0.9 & -1.0 & -1.1 \\
$\widetilde{S}_{\mathrm{g}, \phi}$ & 0.02919 & 0.02201 & 0.01702 & 0.01355 \\
\hline
\end{tabular}

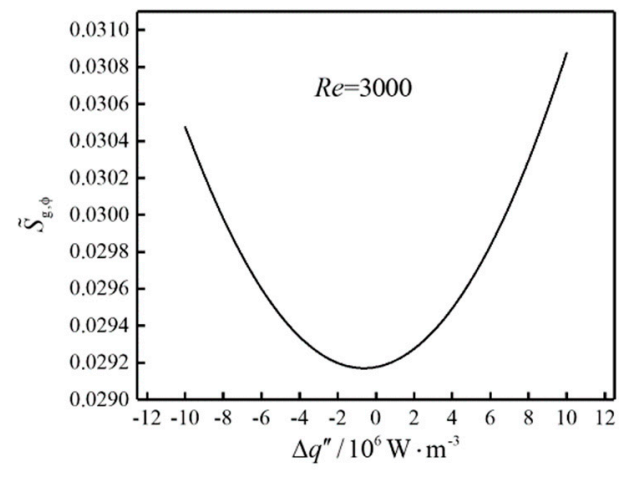

(a) $\operatorname{Re}=3000$

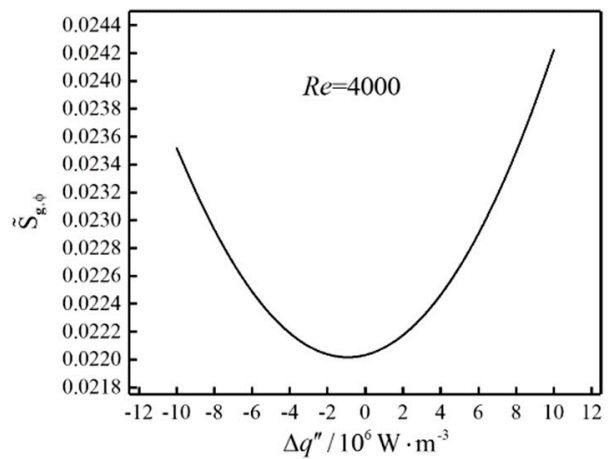

(b) $R e=4000$

Figure 2. Cont. 


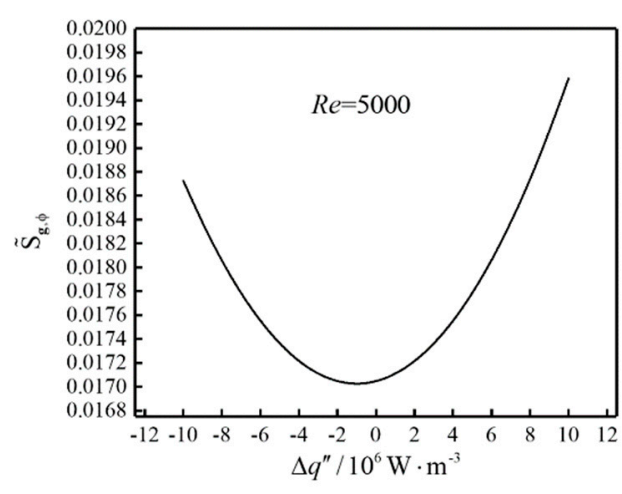

(c) $R e=5000$

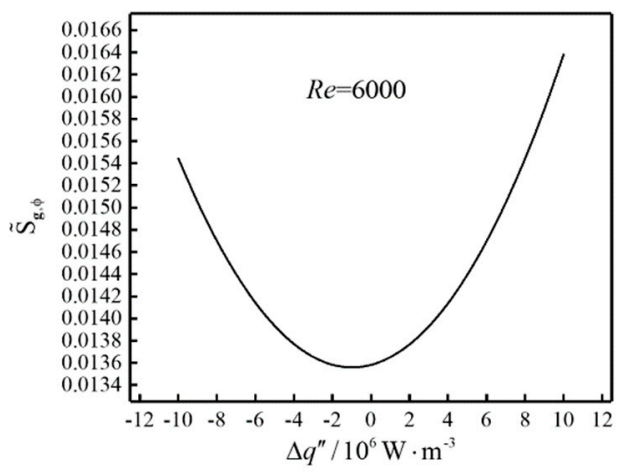

(d) $R e=6000$

Figure 2. The influence of $\Delta q^{\prime \prime}$ on $\widetilde{S}_{\mathrm{g}, \phi}$.

The influence of $\Delta q^{\prime \prime}$ on the average Nusselt number $(\overline{N u})$ of the system is shown in Figure 3. It can be seen from Figure 3 that $\overline{N u}$ increases with the increases of the $R e$ and $\Delta q^{\prime \prime}$.

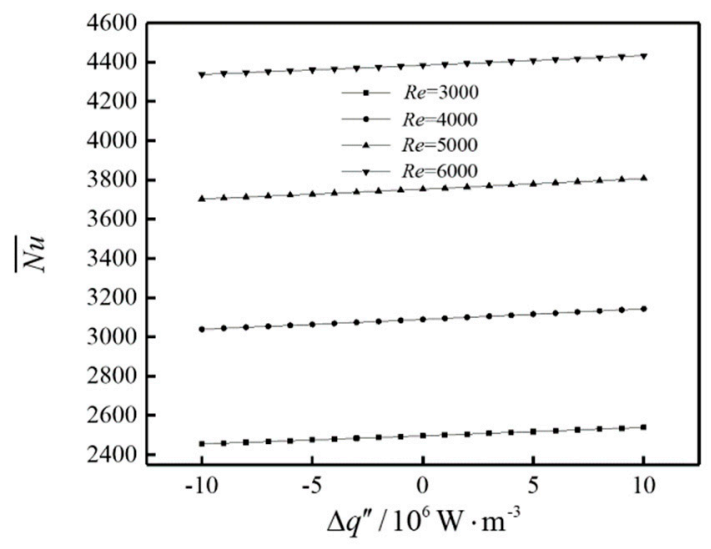

Figure 3. The influence of $\Delta q^{\prime \prime}$ on $\overline{N u}$.

The color maps of the temperature gradient distribution on upper surfaces of heat sources and thermal conduction pedestal at $R e=5000$ are shown in Figure 4. From the figure, as the difference of heat generating intensity increases, the heat generating intensity in the flow direction which is from large to small changes to the distribution which is small to large, the temperature gradient distribution gradually changes from decreasing in flow direction to distributing uniformly around the heat sources. From Figure $4 \mathrm{a}$, although both the heat generating intensity and the temperature gradient decrease in flow direction, the heat generating intensity at channel inlet is relatively larger which makes the heat source near inlet is not well cooled with $\Delta q^{\prime \prime}=-6 \times 10^{6} \mathrm{~W} \cdot \mathrm{m}^{-3}$ the total EGR of system is higher. From Figure $4 \mathrm{~b}$, the temperature gradients around the heat sources gradually decrease in flow direction with $\Delta q^{\prime \prime}=-1 \times 10^{6} \mathrm{~W} \cdot \mathrm{m}^{-3}$. In this case, the cooling of each heat source is optimally balanced, so that the total DEGR of system is the lowest. From Figure 4c, the temperature gradients around the four heat sources are substantially equal, but the heat generating intensity gradually increases one by one in flow direction with $\Delta q^{\prime \prime}=4 \times 10^{6} \mathrm{~W} \cdot \mathrm{m}^{-3}$, which leads to poor cooling of the heat source near channel outlet, so that the total DEGR of system increases. Figure 5 shows the pressure distributions in channel for $\Delta q^{\prime \prime}=0 \mathrm{~W} \cdot \mathrm{m}^{-3}$. From Figure 5, there is little change in the situation of pressure distribution with changes of airflow Reynolds numbers, but the pressure drop in channel rises with the increases of airflow Reynolds numbers. 


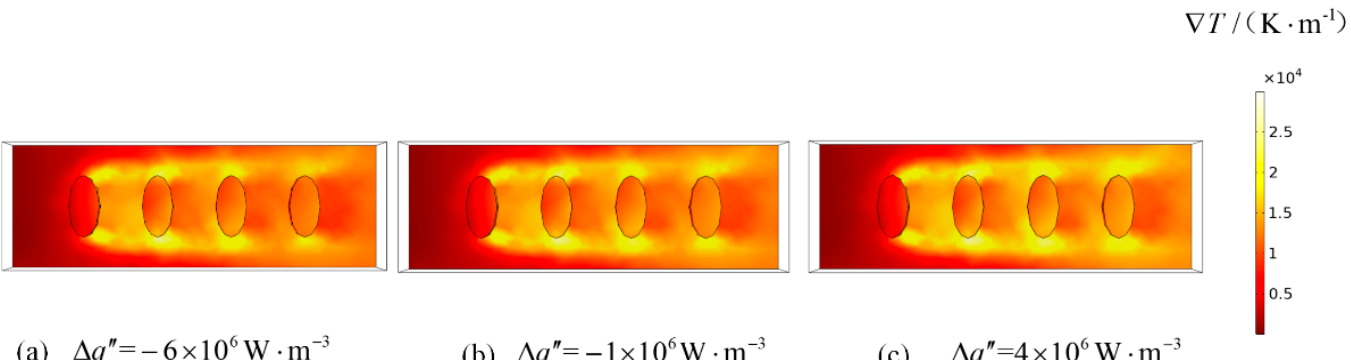

Figure 4. The color maps of temperature gradient distribution on the upper surfaces of discrete elliptical cylinders with heat generating and thermal conduction pedestal $(\operatorname{Re}=5000)$.

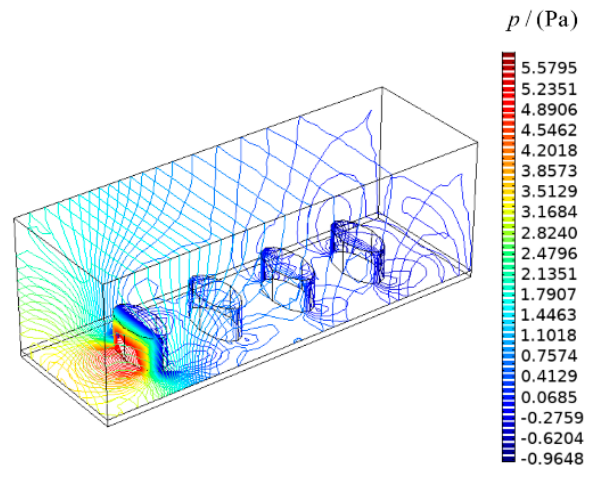

(a) $\operatorname{Re}=3000$



(c) $R e=5000$

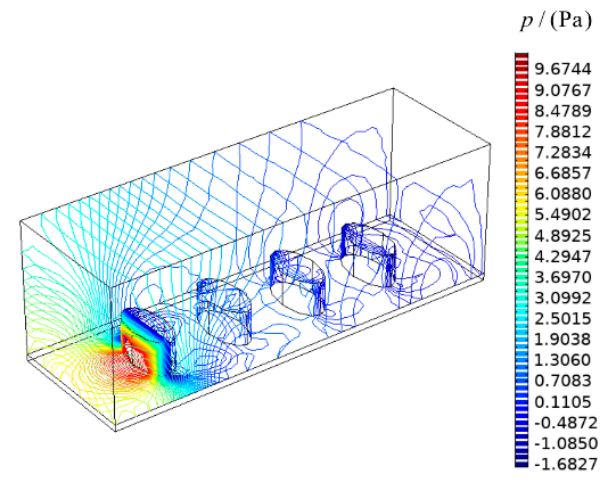

(b) $R e=4000$

$p /(\mathrm{Pa})$

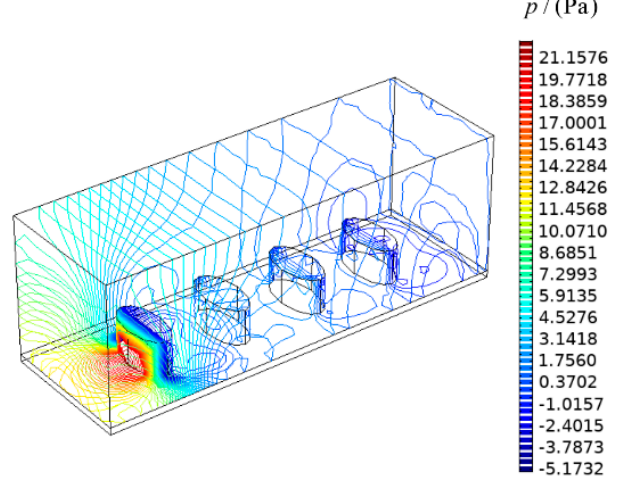

(d) $R e=6000$

Figure 5. Contour plot for pressure in channel $\left(\Delta q^{\prime \prime}=0 \mathrm{~W} \cdot \mathrm{m}^{-3}\right)$.

\subsection{Effects of Thermal Conductivity of Heat Source on Heat Dissipation Performance}

Figure 6 shows the influences of thermal conductivity $\left(\lambda_{\mathrm{s}}\right)$ of each heat source on total DEGR $\left(\widetilde{S}_{\mathrm{g}, \phi}\right)$ of the system under forced convection with fixed equal heat generating intensity of each heat source. As can be seen from the figure, the $\widetilde{S}_{\mathrm{g}, \phi}$ decreases directly and then gradually becomes gentle with the increase of $\lambda_{\mathrm{s}}$ at the same Reynolds number of airflow. When $\lambda_{\mathrm{s}}<150$, the decreasing magnitude is larger, when $\lambda_{\mathrm{s}}$ rises to a certain value, the temperature gradients of heat sources are relatively uniform because the thermal resistances of heat sources are smaller. Then, the effect becomes little that improving the heat dissipation performance and reducing the $\widetilde{S}_{\mathrm{g}, \phi}$ of the system by simultaneously improving the heat conductivities of heat sources. The improvement effect is more obvious when the thermal conductivity of the heat source is lower. 


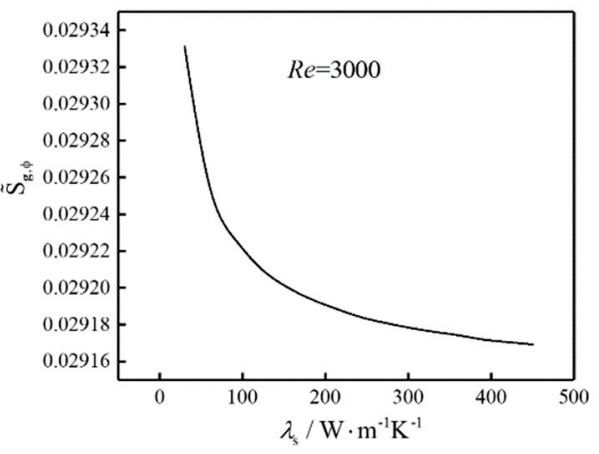

(a) $\operatorname{Re}=3000$

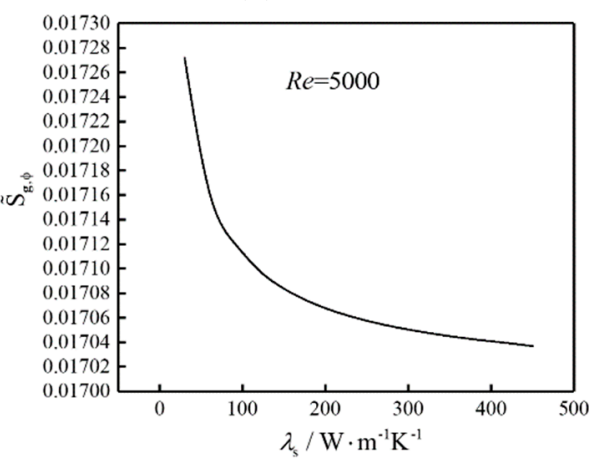

(c) $\operatorname{Re}=5000$

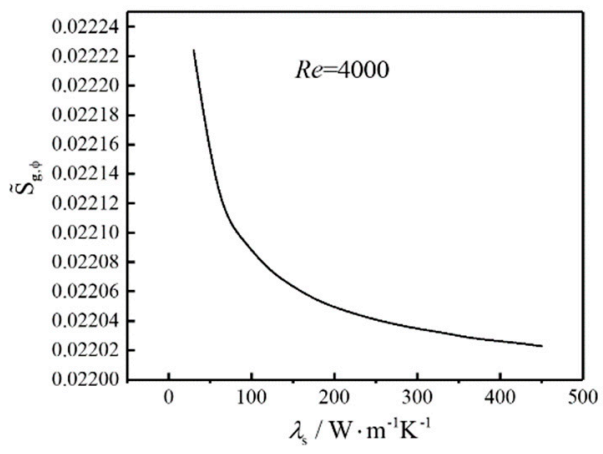

(b) $R e=4000$

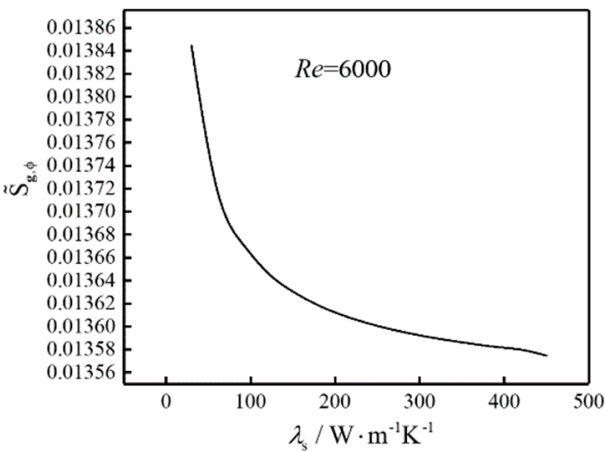

(d) $\operatorname{Re}=6000$

Figure 6. The influence of $\lambda_{\mathrm{s}}$ on $\widetilde{S}_{\mathrm{g}, \phi}$.

To study the change of DEGR of system by changing the difference of thermal conductivity with the fixed equal heat generating intensity of each heat source, the thermal conductivities of heat sources are set as $\lambda_{\mathrm{s}, 1}, \lambda_{\mathrm{s}, 2}, \lambda_{\mathrm{s}, 3}$ and $\lambda_{\mathrm{s}, 4}$, respectively, and distributed with equal difference along flow direction:

$$
\lambda_{\mathrm{s}, 2}-\lambda_{\mathrm{s}, 1}=\lambda_{\mathrm{s}, 3}-\lambda_{\mathrm{s}, 2}=\lambda_{\mathrm{s}, 4}-\lambda_{\mathrm{s}, 3}=\Delta \lambda_{\mathrm{s}}
$$

where $\Delta \lambda_{\mathrm{s}}$ is the difference of thermal conductivity between adjacent heat sources.

Considering the sum of thermal conductivities and the constraints for practical thermal conductivities of materials, it is assumed that the thermal conductivities of heat sources satisfy $30 \leq \lambda_{\mathrm{s}, \mathrm{I}} \leq 450(\mathrm{i}=1,2,3,4)$.

$$
\lambda_{\mathrm{s}, \mathrm{j}}=240+(i-2.5) \Delta \lambda_{\mathrm{s}} \quad\left(-140 \leq \Delta \lambda_{\mathrm{s}, \mathrm{j}} \leq 140\right)
$$

Figure 7 shows the influences of thermal conductivity difference $\left(\Delta \lambda_{\mathrm{s}}\right)$ on total DEGR $\left(\widetilde{S}_{\mathrm{g}, \phi}\right)$ of system when the heat generating intensities are constants. The results show that the total $\widetilde{S}_{\mathrm{g}, \phi}$ of the system decreases first and then rises with the rise of $\Delta \lambda_{\mathrm{s}}$ and $\widetilde{S}_{\mathrm{g}, \phi}$ at $\Delta \lambda_{\mathrm{s}}=-140 \mathrm{~W} \cdot \mathrm{m}^{-1} \cdot \mathrm{K}^{-1}$ is larger than that at $\Delta \lambda_{\mathrm{s}}=140 \mathrm{~W} \cdot \mathrm{m}^{-1} \cdot \mathrm{K}^{-1}$, which means that the thermal conductivity is preferably distributed from small to large in the airflow direction, the device with higher thermal conductivity should be arranged near the channel outlet. Further numerical results listed in Table 3 show that $\left(\Delta \lambda_{s}\right)_{\text {opt }}$ for the same optimization objective are different under different fluid flow conditions. From Table 3 , when the $R e$ of airflow are 2500 and 3000, the optimal difference of thermal conductivity $\left(\left(\Delta \lambda_{s}\right)_{\text {opt }}>0\right)$ makes the total $\widetilde{S}_{\mathrm{g}, \phi}$ reach minimums; when Re of airflow is 4000, 5000 and 6000, the optimal difference of thermal conductivity $\left(\left(\Delta \lambda_{\mathrm{s}}\right)_{\mathrm{opt}}=0 \mathrm{~W} \cdot \mathrm{m}^{-1} \cdot \mathrm{K}^{-1}\right)$ makes the total $\widetilde{S}_{\mathrm{g}, \phi}$ reach minimums. 


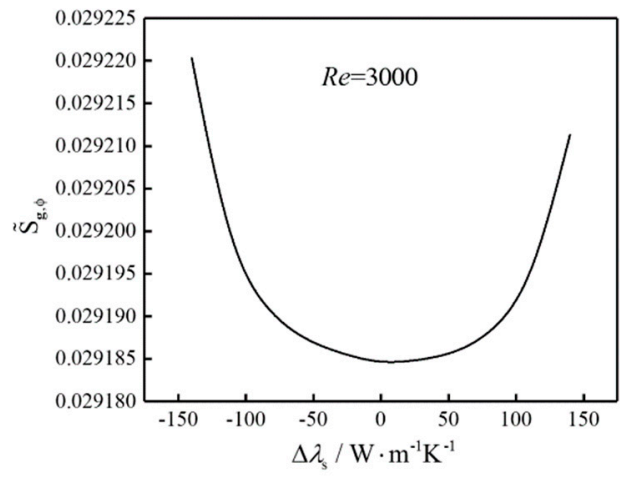

(a) $R e=3000$

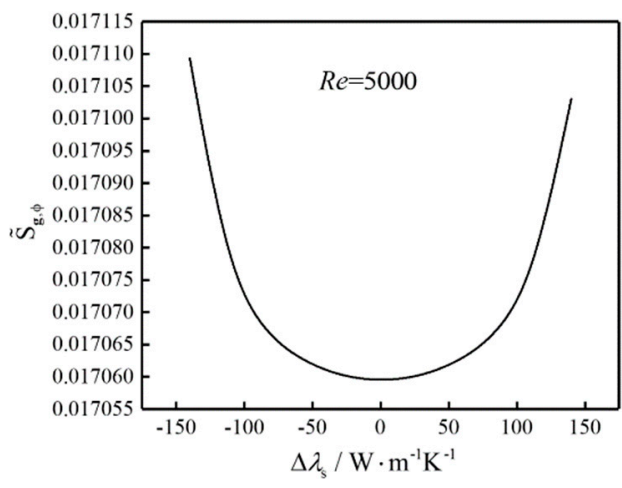

(c) $R e=5000$

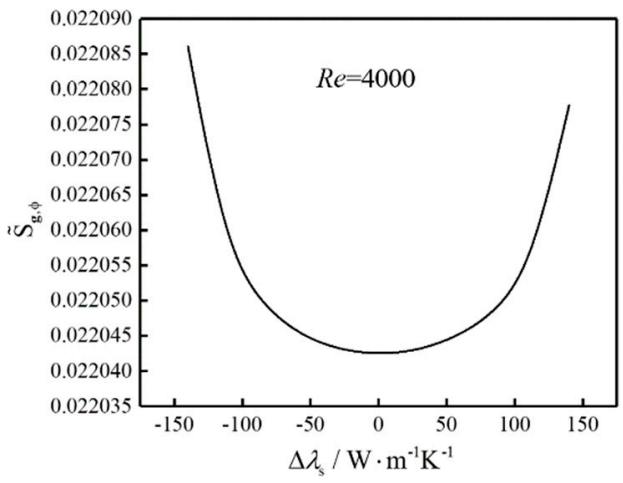

(b) $R e=4000$

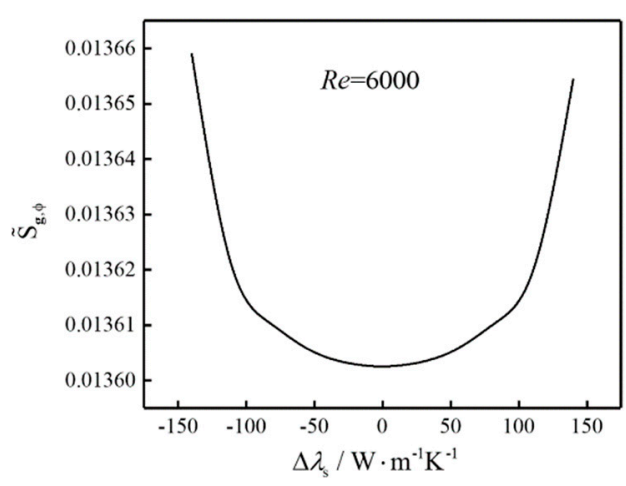

(d) $R e=6000$

Figure 7. The influences of $\Delta \lambda_{\mathrm{s}}$ on $\widetilde{S}_{\mathrm{g}, \phi}$.

Table 3. The optimal distributions of the thermal conductivity for different $R e$.

\begin{tabular}{ccccccc}
\hline $\mathbf{R e}$ & $\mathbf{2 5 0 0}$ & $\mathbf{3 0 0 0}$ & $\mathbf{3 5 0 0}$ & $\mathbf{4 0 0 0}$ & $\mathbf{5 0 0 0}$ & $\mathbf{6 0 0 0}$ \\
\hline$\left(\Delta \lambda_{\mathrm{s}}\right)_{\mathrm{opt}} / \mathrm{W} \cdot \mathrm{m}^{-1} \cdot \mathrm{K}^{-1}$ & 4 & 6 & 0 & 0 & 0 & 0 \\
$\widetilde{S}_{\mathrm{g}, \phi}$ & 0.03382 & 0.02919 & 0.02530 & 0.02201 & 0.01702 & 0.01355 \\
\hline
\end{tabular}

This occurs because the discrete elliptical cylinders with heat generating reinforce the flow resistance in the channel but cause secondary vortexes at the same time. When the Re of airflow is 3000 and $\Delta \lambda_{\mathrm{s}}$ is larger than 0 , the thermal conductivity of heat source increases one by one appropriately to reduce the thermal resistance for thermal conduction in corresponding regions along flow direction, and the temperature gradients decrease obviously resulted from the secondary vortexes which enhance heat transfer locally, so the cooling requirements of all parts can be met better and appropriately, and the total DEGR of system decreases. With the Re of airflow increasing, the forced convective condition changes, so the heat transfer including heat conduction and convective heat transfer should be adapted coordinately to benefit heat flow for EGM and the total $\widetilde{S}_{g, \phi}$ of system are the smallest when the thermal conductivities of heat sources are equal.

From Figures 2, 6 and 7, the impacts of distributions about heat generating intensity and thermal conductivity is $6 \%$ and $1 \%$ roughly. The higher the Reynolds number, the smaller the maximum temperature $\left(T_{\max }\right)$ of electrical device. At the same $R e$, as the $\Delta q^{\prime \prime}$ and $\Delta \lambda_{\mathrm{s}}$ increase, the $T_{\max }$ decreases firstly and then increases, the $\Delta q^{\prime \prime}$ opt and the $\left(\Delta \lambda_{\mathrm{s}}\right)_{\text {opt }}$ make $T_{\max }$ minimum, and the $\Delta q^{\prime \prime}{ }_{\text {opt }}$ and $\left(\Delta \lambda_{\mathrm{s}}\right)_{\mathrm{opt}}$ are different, respectively, for different performance indicators. 


\section{Conclusions}

In this work, a 3-D heat dissipation model of discrete elliptical cylinders with heat generation on a thermal conduction pedestal with forced convection is established. The effects of heat generation intensity distribution and thermal conductivity distribution on the total DEGR of system are investigated, respectively. The results bring to light that when the total heat generating intensity of heat sources is specified, there is an optimal distribution of the heat generation intensity that makes the total DEGR smallest. The minimums of total DEGR corresponding to optimal differences of heat generating intensity are different at different airflow velocities. The heat generating intensity can be decreased one by one appropriately in flow direction to achieve the best effect.

When the thermal conductivity of each heat source is equal, the total DEGR of system decreases with the simultaneous rise of the thermal conductivity of each heat source and then gradually becomes equilibrium. The thermal conductivity of each heat source can be appropriately increased to enhance heat dissipation.

When the sum of thermal conductivities of heat sources is fixed, there are optimal distributions of thermal conductivity that minimize the DEGR of system. When the Reynolds number of airflow is smaller, the thermal conductivity of heat source can be increased one by one appropriately in flow direction to achieve the best effect; while the Reynolds number of airflow is larger, the thermal conductivity of each heat source should be equalized to achieve the best effect.

Author Contributions: R.W., Z.X., Y.Y., L.C. prepared the manuscript together. All authors have read and agreed to the published version of the manuscript.

Funding: This research was funded by National Natural Science Foundation of China grant number 51579244.

Acknowledgments: This work was supported by the National Natural Science Foundation of China (Grant Nos. 51579244, 51979278 and 51506220). The authors wish to thank the reviewers for their careful, unbiased and constructive suggestions, which led to this revised manuscript.

Conflicts of Interest: The authors declare no conflict of interest.

\section{Nomenclature}

\begin{tabular}{|c|c|}
\hline$b$ & Ratio \\
\hline$C_{\varepsilon 1}, C_{\varepsilon 2}, C_{\mu}$ & Empirical constants \\
\hline$c$ & Constant pressure specific heat capacity, $\mathrm{J} \cdot \mathrm{kg}^{-1} \cdot \mathrm{K}^{-1}$ \\
\hline$F$ & Volume force vector, $\mathrm{N}$ \\
\hline$H$ & Thickness of pedestal, $\mathrm{m}$ \\
\hline$H_{S}$ & Height of heat source, $\mathrm{m}$ \\
\hline$\widetilde{H}$ & Dimensionless height \\
\hline I & Unit matrix \\
\hline$k$ & Turbulent kinetic energy, J \\
\hline$L$ & Length of pedestal, $\mathrm{m}$ \\
\hline$L_{a}$ & Short axis of ellipse, $\mathrm{m}$ \\
\hline$L_{b}$ & Long axis of ellipse, $\mathrm{m}$ \\
\hline$P_{k}$ & Generation term of turbulent kinetic energy \\
\hline$P_{t}$ & The total heating power of heat sources \\
\hline$Q$ & Heat source item including viscous dissipation and pressure work, $\mathrm{W} \cdot \mathrm{m}^{-3}$ \\
\hline$q$ & Heat flux vector, $\mathrm{W} \cdot \mathrm{m}^{-2}$ \\
\hline$q "$ & Heat generating intensity, $\mathrm{W} \cdot \mathrm{m}^{-3}$ \\
\hline$S_{\mathrm{g}, \phi}$ & Entropy generation rate, $\mathrm{W} \cdot \mathrm{K}^{-1}$ \\
\hline$\widetilde{S}_{\mathrm{g}, \phi}$ & Dimensionless entropy generation rate \\
\hline $\mathrm{T}$ & Matrix transpose operator symbol \\
\hline$T$ & Temperature, $\mathrm{K}$ \\
\hline$\widetilde{T}$ & Dimensionless hot spot temperature \\
\hline$u$ & Velocity vector, $\mathrm{m} / \mathrm{s}$ \\
\hline W & Width of pedestal, $\mathrm{m}$ \\
\hline
\end{tabular}




\section{Greek Symbols}

$\varepsilon \quad$ Turbulent dissipation rate, $\%$

$\lambda \quad$ Thermal conductivity, $\mathrm{W} \cdot \mathrm{m}^{-1} \cdot \mathrm{K}^{-1}$

$\mu \quad$ Dynamic viscosity coefficient, Pa.s

$\mu_{\mathrm{T}} \quad$ Turbulent viscosity coefficient, Pa.s

$\rho \quad$ Density, $\mathrm{kg} \cdot \mathrm{m}^{-3}$

$\sigma_{\mathrm{k}}, \sigma_{\mathcal{\varepsilon}} \quad$ Empirical constants

\section{Subscripts}

b Heat conductive pedestal

f Fluid

i Number of heat source

in Inlet

opt Optimum

s Heat source

\section{Abbreviations}

EGM Entropy generation minimization

EGR Entropy generation rate

DEGR dimensionless entropy generation rate

\section{References}

1. Yousef, A.; Mohammad, Z.T.; Mohammad, M.H.; Nima, G. Effect of a micro heat sink geometric design on thermo-hydraulic performance: A review. Appl. Therm. Eng. 2020, 170, 114974.

2. Khattak, Z.; Ali, H.M. Air cooled heat sink geometries subjected to forced flow: A critical review. Int. J. Heat Mass Transf. 2019, 130, 141-161. [CrossRef]

3. Bejan, A. Street network theory of organization in nature. J. Adv. Transp. 1996, 30, 85-107. [CrossRef]

4. Bejan, A. Constructal-theory network of conducting paths for cooling a heat generating volume. Int. J. Heat Mass Transf. 1997, 40, 799-816. [CrossRef]

5. Reis, A. Constructal theory: From engineering to physics, and how flow systems develop shape and structure. Trans. ASME Appl. Mech. Rev. 2006, 59, 269-282. [CrossRef]

6. Chen, L.G. Progress in study on constructal theory and its applications. Sci. China Tech. Sci. 2012, 55, 802-820. [CrossRef]

7. Bejan, A. Constructal thermodynamics. Int. J. Heat Tech. 2016, 34, S1-S8. [CrossRef]

8. Bejan, A.; Errera, M.R. Complexity, organization, evolution, and constructal law. J. Appl. Phys. 2016, 119, 074901. [CrossRef]

9. Chen, L.G.; Feng, H.J.; Xie, Z.H. Generalized thermodynamic optimization for iron and steel production processes: A theoretical exploration and application cases. Entropy 2016, 18, 353. [CrossRef]

10. Feng, H.J.; Chen, L.G.; Xie, Z.H. Multi-disciplinary, multi-objective and multi-scale constructal optimizations for heat and mass transfer processes performed in Naval University of Engineering, a review. Int. J. Heat Mass Transf. 2017, 115, 86-98. [CrossRef]

11. Lorente, S. The constructal law: From microscale to urban-scale design. Annu. Rev. Heat Transf. 2017, 19, 335-368. [CrossRef]

12. Chen, L.G.; Xiao, Q.H.; Feng, H.J. Constructal optimizations for heat and mass transfers based on the entransy dissipation extremum principle, performed at the Naval University of Engineering: A review. Entropy 2018, 20, 74. [CrossRef]

13. Bejan, A. Constructal law, twenty years after. Proc. Rom. Acad. Ser. A Math. Phys. Tech. Sci. Inform. Sci. 2018, 18, 309-311.

14. You, J.; Feng, H.J.; Chen, L.G.; Xie, Z.H. Constructal optimization for cooling a nonuniform heat generating disc-shaped area by conduction. Entropy 2018, 20, 685. [CrossRef] 
15. Lorente, S.; Bejan, A. Current trends in constructal law and evolutionary design. Heat Transf. Asian Res. 2019, 48, 357-389. [CrossRef]

16. Bejan, A.; Gunes, U.; Sahin, B. The evolution of air and maritime transport. Appl. Phys. Rev. 2019, 6, 021319. [CrossRef]

17. Bejan, A. The evolving design of our life. Interdiscip. J. Lands. Archit. 2019, 9, 8-13.

18. Chen, L.G.; Feng, H.J.; Xie, Z.H.; Sun, F.R. Progress of constructal theory in China over the past decade. Int. J. Heat Mass Transf. 2019, 130, 393-419. [CrossRef]

19. Zhang, F.Y.; Feng, H.J.; Chen, L.G.; You, J.; Xie, Z.J. Constructal design of an arrow-shaped high thermal conductivity channel in a square heat generation body. Entropy 2020, 22, 475. [CrossRef]

20. Bejan, A.; Lorente, S. Design with Constructal Theory; Wiley: New Jersey, NJ, USA, 2008.

21. Rocha, L.A.O.; Lorente, S.; Bejan, A. Constructal Law and the Unifying Principle of Design; Springer: Berlin, Germany, 2013.

22. Chen, L.G.; Feng, H.J. Multi-objective Constructal Optimization for Flow and Heat and Mass Transfer Processes; Science Press: Beijing, China, 2016. (In Chinese)

23. Bejan, A. Freedom and Evolution; Springer Science and Business Media LLC: Berlin, Germany, 2020.

24. Chen, L.G.; Yang, A.B.; Feng, H.J.; Xia, S.J. Constructal designs for eight types of heat sinks. Sci. China Technol. Sci. 2020, 63, 879-911. [CrossRef]

25. Bejan, A. General criterion for rating heat exchanger performance. Int. J. Heat Mass Transf. 1978, 21, $655-658$. [CrossRef]

26. Bejan, A. Two thermodynamic optima in the design and operation of thermal energy storage systems. Trans. ASME, J. Heat Transf. 1978, 100, 708-712. [CrossRef]

27. Torabi, M.; Zhang, K.; Karimi, N.; Peterson, G.P. Entropy generation in thermal systems with solid structures-A concise review. Int. J. Heat Mass Transf. 2016, 97, 917-931. [CrossRef]

28. Ge, Y.L.; Chen, L.G.; Sun, F.R. Progress in finite time thermodynamic studies for internal combustion engine cycles. Entropy 2016, 18, 139. [CrossRef]

29. Wu, Z.X.; Chen, L.G.; Feng, H.J. Thermodynamic optimization for an endoreversible Dual-Miller cycle (DMC) with finite speed of piston. Entropy 2018, 20, 165. [CrossRef]

30. Roach, T.N.F.; Salamon, P.; Nulton, J.; Andresen, B.; Felts, B.; Haas, A.; Calhoun, S.; Robinett, N.; Rohwer, F. Application of finite-time and control thermodynamics to biological processes at multiple scales. J. Non-Equilib. Thermodyn. 2018, 43, 193-210. [CrossRef]

31. Feng, Y.L.; Chen, L.G.; Meng, F.K.; Sun, F.R. Influences of Thomson effect on performance of thermoelectric generator-driven thermoelectric heat pump combined device. Entropy 2018, 20, 29. [CrossRef]

32. Pourkiaei, S.M.; Ahmadi, M.H.; Sadeghzadeh, M.; Moosavi, S.; Pourfayaz, F.; Chen, L.G.; Yazdi, M.A.; Kumar, R. Thermoelectric cooler and thermoelectric generator devices: A review of present and potential applications, modeling and materials. Energy 2019, 186, 115849. [CrossRef]

33. Li, W.S.; Zhao, Y.X.; Wang, Q.; Zhou, J. Twenty years of entropy research: A bibliometric overview. Entropy 2019, 21, 694. [CrossRef]

34. Zhu, F.L.; Chen, L.G.; Wang, W.H. Thermodynamic analysis of an irreversible Maisotsenko reciprocating Brayton cycle. Entropy 2018, 20, 167. [CrossRef]

35. Zhang, L.; Chen, L.G.; Xia, S.J.; Wang, C.; Sun, F.R. Entropy generation minimization for reverse water gas shift (RWGS) reactor. Entropy 2018, 20, 415. [CrossRef]

36. Chen, L.G.; Zhang, L.; Xia, S.J.; Sun, F.R. Entropy generation minimization for hydrogenation of $\mathrm{CO}_{2}$ to light olefins. Energy 2018, 147, 187-196. [CrossRef]

37. Li, P.L.; Chen, L.G.; Xia, S.J.; Zhang, L. Entropy generation rate minimization for in methanol synthesis via $\mathrm{CO}_{2}$ hydrogenation reactor. Entropy 2019, 21, 174. [CrossRef]

38. Chen, L.G.; Xia, S.J. Progresses in generalized thermodynamic dynamic-optimization of irreversible processes. Sci. Sin. Technol. 2019, 49, 981-1022. (In Chinese) [CrossRef]

39. Chen, L.G.; Xia, S.J.; Feng, H.J. Progress in generalized thermodynamic dynamic-optimization of irreversible cycles. Sci. Sin. Technol. 2019, 49, 1223-1267. (In Chinese) [CrossRef]

40. Zhang, L.; Xia, S.J.; Chen, L.G.; Ge, Y.L.; Wang, C.; Feng, H.J. Entropy generation rate minimization for hydrocarbon synthesis reactor from carbon dioxide and hydrogen. Int. J. Heat Mass Transf. 2019, 137, 1112-1123. [CrossRef] 
41. Chen, L.G.; Ge, Y.L.; Liu, C.; Feng, H.J.; Lorenzini, G. Performance of universal reciprocating heat-engine cycle with variable specific heats ratio of working fluid. Entropy 2020, 22, 397. [CrossRef]

42. Li, P.L.; Chen, L.G.; Xia, S.J.; Zhang, L.; Kong, R.; Ge, Y.L.; Feng, H.J. Entropy generation rate minimization for steam methane reforming reactor heated by molten salt. Energy Rep. 2020, 6, 685-697. [CrossRef]

43. Meng, Z.W.; Chen, L.G.; Wu, F. Optimal power and efficiency of multi-stage endoreversible quantum Carnot heat engine with harmonic oscillators at the classical limit. Entropy 2020, 22, 397. [CrossRef]

44. Bejan, A. Entropy Generation through Heat and Fluid Flow; Wiley: New York, NY, USA, 1982.

45. Sieniutycz, S.; Szwast, Z. Optimizing Thermal, Chemical and Environmental Systems; Elsevier: Amsterdam, The Netherlands, 2018.

46. Haseli, Y. Entropy Analysis in Thermal Engineering Systems; Elsevier: London, UK, 2019.

47. Chen, L.G.; Wu, C.; Sun, F.R. Finite time thermodynamic optimization or entropy generation minimization of energy systems. J. Non-Equilib. Thermodyn. 1999, 24, 327-359. [CrossRef]

48. Chen, L.G.; Sun, F.R. Advances in Finite Time Thermodynamics: Analysis and Optimization; Nova Science Publishers: New York, NY, USA, 2004.

49. Kingston, D.; Razzitte, A.C. Entropy generation minimization in Dimethyl Ether synthesis: A case study. J. Non-Equilib. Thermodyn. 2018, 43, 111-120. [CrossRef]

50. Paéz-Hernández, R.T.; Chimal-Eguía, J.C.; Sánchez-Salas, N.; Ladino-Luna, D. General properties for an Agrawal thermal engine. J. Non-Equilib. Thermodyn. 2018, 43, 131-140. [CrossRef]

51. Schwalbe, K.; Hoffmann, K.H. Novikov engine with fluctuating heat bath temperature. J. Non-Equilib. Thermodyn. 2018, 43, 141-150. [CrossRef]

52. Feidt, M.; Costea, M. From finite time to finite physical dimensions thermodynamics: The Carnot engine and Onsager's relations revisited. J. Non-Equilib. Thermodyn. 2018, 43, 151-162. [CrossRef]

53. Schwalbe, K.; Hoffmann, K.H. Optimal control of an endoreversible solar power plant. J. Non-Equilib. Thermodyn. 2018, 43, 255-272. [CrossRef]

54. Zaeva, M.A.; Tsirlin, A.M.; Didina, O.V. Finite time thermodynamics: Realizability domain of heat to work converters. J. Non-Equilib. Thermodyn. 2019, 44, 181-191. [CrossRef]

55. Raman, R.; Kumar, N. Performance analysis of Diesel cycle under efficient power density condition with variable specific heat of working fluid. J. Non-Equilib. Thermodyn. 2019, 44, 405-416. [CrossRef]

56. Schwalbe, K.; Hoffmann, K.H. Stochastic Novikov engine with Fourier heat transport. J. Non-Equilib. Thermodyn. 2019, 44, 417-424. [CrossRef]

57. Marsik, F.; Weigand, B.; Tomas, M.; Tucek, O.; Novotny, P. On the efficiency of electrochemical devices from the perspective of endoreversible thermodynamics. J. Non-Equilib. Thermodyn. 2019, 44, 425-438. [CrossRef]

58. Chen, L.G.; Li, J. Thermodynamic Optimization Theory for Two-Heat-Reservoir Cycles; Science Press: Beijing, China, 2020.

59. Boikov, S.Y.; Andresen, B.; Akhremenkov, A.A.; Tsirlin, A.M. Evaluation of irreversibility and optimal organization of an integrated multi-stream heat exchange system. J. Non-Equilib. Thermodyn. 2020, 45, 155-171. [CrossRef]

60. Ding, Z.M.; Ge, Y.L.; Chen, L.G.; Feng, H.J.; Xia, S.J. Optimal performance regions of Feynman's ratchet engine with different optimization criteria. J. Non-Equilib. Thermodyn. 2020, 45, 191-207. [CrossRef]

61. Yang, A.B.; Chen, L.G.; Xie, Z.H.; Feng, H.J.; Sun, F.R. Constructal operation cost minimization for in-line cylindrical pin-fin heat sinks. Int. J. Heat Mass Transf. 2019, 129, 562-568. [CrossRef]

62. Mustafa, A.W. Constructal design of multi-scale diamond-shaped pin fins cooled by mixed convection. Int. J. Therm. Sci. 2019, 145, 106018. [CrossRef]

63. Hazarika, S.A.; Deshmukhya, T.; Bhanja, D.; Nath, S. A novel optimum constructal fork-shaped fin array design for simultaneous heat and mass transfer application in a space-constrained situation. Int. J. Therm. Sci. 2020, 150, 106225. [CrossRef]

64. Shi, H.N.; Xie, Z.H.; Chen, L.G.; Sun, F.R. Constructal optimization for line-to-line vascular based on entropy generation minimization principle. Int. J. Heat Mass Transf. 2018, 126, 848-854. [CrossRef]

65. Lu, Z.H.; Zhang, K.; Liu, J.X.; Li, F. Effect of branching level on the performance of constructal theory based Y-shaped liquid cooling heat sink. Appl. Therm. Eng. 2020, 168, 114824. [CrossRef]

66. Feng, H.J.; Chen, L.G.; Xia, S.J. Constructal design for disc-shaped heat exchanger with maximum thermal efficiency. Int. J. Heat Mass Transf. 2019, 130, 740-746. [CrossRef] 
67. Feng, H.J.; Chen, L.G.; Wu, Z.X.; Xie, Z.J. Constructal design of a shell-and-tube heat exchanger for organic fluid evaporation process. Int. J. Heat Mass Transf. 2019, 131, 750-756. [CrossRef]

68. Wu, Z.X.; Feng, H.J.; Chen, L.G.; Ge, Y.L. Performance optimization of a condenser in ocean thermal energy conversion (OTEC) system based on constructal theory and multi-objective genetic algorithm. Entropy 2020, 22, 641. [CrossRef]

69. Ariyo, D.O.; Bello-Ochende, T. Constructal design of subcooled microchannel heat exchangers. Int. J. Heat Mass Transf. 2020, 146, 118835. [CrossRef]

70. Chen, L.G.; You, J.; Feng, H.J.; Xie, Z.H. Constructal optimization for “disc-point” heat conduction with nonuniform heat generating. Int. J. Heat Mass Transf. 2019, 134, 1191-1198. [CrossRef]

71. You, J.; Feng, H.J.; Chen, L.G.; Xie, Z.H. Constructal design of nonuniform heat generating area based on triangular elements: A case of entropy generation minimization. Int. J. Therm. Sci. 2019, 139, 403-412. [CrossRef]

72. Cai, C.G.; Feng, H.J.; Chen, L.G.; Wu, Z.X.; Xie, Z.J. Constructal design of a shell-and-tube evaporator with ammonia-water working fluid. Int. J. Heat Mass Transf. 2019, 135, 541-547. [CrossRef]

73. Xie, Z.J.; Feng, H.J.; Chen, L.G.; Wu, Z.X. Constructal design for supercharged boiler evaporator. Int. J. Heat Mass Transf. 2019, 138, 571-579. [CrossRef]

74. Wu, Z.X.; Feng, H.J.; Chen, L.G.; Xie, Z.J.; Cai, C.G. Pumping power minimization of an evaporator in ocean thermal energy conversion system based on constructal theory. Energy 2019, 181, 974-984. [CrossRef]

75. Feng, H.J.; Xie, Z.J.; Chen, L.G.; Wu, Z.X.; Xia, S.J. Constructal design for supercharged boiler superheater. Energy 2020, 191, 116484. [CrossRef]

76. You, J.; Feng, H.J.; Chen, L.G.; Xie, Z.H.; Xia, S.J. Constructal design and experimental validation of a non-uniform heat generating body with rectangular cross-section and parallel circular cooling channels. Int. J. Heat Mass Transf. 2020, 148, 119028. [CrossRef]

77. Pedroti, V.A.; de Escobar, C.C.; dos Santos, E.D.; Souza, J.A. Thermal analysis of tubular arrangements submitted to external flow using constructal theory. Int. Comm. Heat Mass Transf. 2020, 111, 104458. [CrossRef]

78. Wu, Z.X.; Feng, H.J.; Chen, L.G.; Xie, Z.J.; Cai, C.G.; Xia, S.J. Optimal design of dual-pressure turbine in OTEC system based on constructal theory. Energy Convers. Manage. 2019, 201, 112179. [CrossRef]

79. Wu, Z.X.; Feng, H.J.; Chen, L.G.; Tang, W.; Shi, J.Z.; Ge, Y.L. Constructal thermodynamic optimization for ocean thermal energy conversion system with dual-pressure organic Rankine cycle. Energy Convers. Manage. 2020, 210, 112727. [CrossRef]

80. Da Silva, A.K.; Gosselin, L. Constructal peripheral cooling of a rectangular heat-generating area. Trans. ASME J. Electron. Pack. 2006, 128, 432-440. [CrossRef]

81. Gong, S.W.; Chen, L.G.; Xie, Z.H.; Feng, H.J.; Sun, F.R. Constructal optimization of cylindrical heat sources with forced convection based on entransy dissipation minimization. Sci. China Techhol. Sci. 2016, 59, 631-639. [CrossRef]

82. Gong, S.W.; Chen, L.G.; Feng, H.J.; Xie, Z.H.; Sun, F.R. Constructal optimization of cylindrical heat sources surrounded with a fin based on minimization of hot spot temperature. Int. Comm. Heat Mass Transf. 2015, 68, 1-7. [CrossRef]

83. Gong, S.W. Optimal Design of Cylindrical Heat Sources Based on Constructal Theory. Master's Thesis, Naval University of Engineering, Wuhan, China, 2015. (In Chinese)

84. Jassim, E.; Muzychka, Y.S. Optimal distribution of heat sources in convergent channels cooled by laminar forced convection. Trans. ASME, J. Heat Transf. 2010, 132, 011701. [CrossRef]

85. Tye-Gingras, M.; Gosselin, L.; da Silva, A.K. Synchronizing time-varying discrete heating elements in forced convection for minimal thermal resistance. Int. J. Heat Mass Transf. 2010, 53, 4917-4926. [CrossRef]

86. Shi, Z.Y.; Dong, T. A synthetic layout optimization of discrete heat sources flush mounted on a laminar flow cooled flat plate based on the constructal law. Energy Convers. Manage. 2015, 106, 300-307. [CrossRef]

87. Fan, X.D. Constructal Study on Multi-scale Heat Source and Heat Sink. Master's Thesis, Naval University of Engineering, Wuhan, China, 2015. (In Chinese)

88. Wang, G. Heat Dissipation Analysis and Constructal Design of Columnar Heat Generation Components. Master's Thesis, Naval University of Engineering, Wuhan, China, 2015. (In Chinese)

89. Sarper, B.; Saglam, M.; Aydin, O. Constructal placement of discrete heat sources with different lengths in vertical ducts under natural and mixed convection. Trans. ASME, J. Heat Transf. 2018, 140, 121401. [CrossRef] 
90. Chen, K.; Xing, J.W.; Wang, S.F.; Song, M.X. Heat source layout optimization in two- dimensional heat conduction using simulated annealing method. Int. J. Heat Mass Transf. 2017, 108 Pt A, 210-219. [CrossRef]

91. Aslan, Y.; Puskely, J.; Yarovoy, A. Heat source layout optimization for two-dimensional heat conduction using iterative reweighted L1-norm convex minimization. Int. J. Heat Mass Transf. 2018, 122, 432-441. [CrossRef]

92. Armaghani, T.; Rashad, A.M.; Vahidifar, O.; Mishra, S.R.; Chamkha, A.J. Effects of discrete heat source location on heat transfer and entropy generation of nanofluid in an open inclined L-shaped cavity. Int. J. Numer. Methods Heat Fluid Flow 2019, 29, 1363-1377. [CrossRef]

93. Khan, I.; Khan, W.A.; Qasim, M.; Afridi, I.; Alharbi, S.O. Thermodynamic analysis of entropy generation minimization in thermally dissipating flow over a thin needle moving in a parallel free stream of two Newtonian fluids. Entropy 2019, 21, 74. [CrossRef]

94. Alsaadi, F.E.; Muhammad, K.; Hayat, T.; Alsaedi, A. Numerical study of melting effect with entropy generation minimization in flow of carbon nanotubes. J. Therm. Anal. Calorim. 2020, 140, 321-329. [CrossRef]

95. Hayat, T.; Qayyum, S.; Alsaedi, A.; Ahmad, B. Entropy generation minimization: Darcy-Forchheimer nanofluid flow due to curved stretching sheet with partial slip. Int. Comm. Heat Mass Transf. 2020, 111, 104445. [CrossRef]

96. Japar, W.M.A.A.; Sidik, N.A.C.; Asako, Y. Entropy generation minimization in sinusoidal cavities-ribs microchannel heat sink via secondary channel geometry. CFD Lett. 2019, 11, 1-10.

97. Mohapatra, T.; Rout, S.K. Experimental investigation and performance optimization of a cross flow heat exchanger by entropy generation minimization approach. J. Therm. Eng. 2019, 5, 1-12.

98. Han, Y.; Wang, X.S.; Zhang, H.N.; Chen, Q.Z.; Zhang, Z. Multi-objective optimization of helically coiled tube heat exchanger based on entropy generation theory. Int. J. Therm. Sci. 2019, 147, 106150. [CrossRef]

99. Nemati, H.; Moghimi, M.A.; Sapin, P.; Markides, C.N. Shape optimisation of air-cooled finned-tube heat exchangers. Int. J. Therm. Sci. 2020, 148, 106233. [CrossRef]

100. COMSOL Multiphysics User's Guide, Version 5.2a; COMSOL Incorporated: Stockholm, Sweden, 2012; pp. 103-147.

(C) 2020 by the authors. Licensee MDPI, Basel, Switzerland. This article is an open access article distributed under the terms and conditions of the Creative Commons Attribution (CC BY) license (http://creativecommons.org/licenses/by/4.0/). 